\title{
Escherichia coli genes that reduce the lethal effects of stress
}

\author{
Xiulin Han ${ }^{1}$, Angella Dorsey-Oresto ${ }^{2}$, Muhammad Malik², Jian-Ying Wang ${ }^{2}$, Karl Drlica ${ }^{2}$, Xilin Zhao ${ }^{2}$, Tao $^{2}{ }^{1,2^{*}}$
}

\begin{abstract}
Background: The continuing emergence of antimicrobial resistance requires the development of new compounds and/or enhancers of existing compounds. Genes that protect against the lethal effects of antibiotic stress are potential targets of enhancers. To distinguish such genes from those involved in drug uptake and efflux, a new susceptibility screen is required.

Results: Transposon (Tn5)-mediated mutagenesis was used to create a library of Escherichia coli mutants that was screened for hypersensitivity to the lethal action of quinolones and counter-screened to have wild-type bacteriostatic susceptibility. Mutants with this novel "hyperlethal" phenotype were found. The phenotype was transferable to other E. coli strains by P1-mediated transduction, and for a subset of the mutants the phenotype was complemented by the corresponding wild-type gene cloned into a plasmid. Thus, the inactivation of these genes was responsible for hyperlethality. Nucleotide sequence analysis identified 14 genes, mostly of unknown function, as potential factors protecting from lethal effects of stress. The 14 mutants were killed more readily than wild-type cells by mitomycin C and hydrogen peroxide; nine were also more readily killed by UV irradiation, and several exhibited increased susceptibility to killing by sodium dodecyl sulfate. No mutant was more readily killed by high temperature.

Conclusions: A new screening strategy identified a diverse set of $E$. coli genes involved in the response to lethal antimicrobial and environmental stress, with some genes being involved in the response to multiple stressors. The gene set, which differed from sets previously identified with bacteriostatic assays, provides an entry point for obtaining small-molecule enhancers that will affect multiple antimicrobial agents.
\end{abstract}

\section{Background}

The emergence of antimicrobial resistance is severely limiting treatment options for many important infectious diseases $[1,2]$. Traditionally the problem of antimicrobial resistance has been approached by developing new compounds having increased potency. Unfortunately, development of new compounds is not keeping pace with the emergence of antibiotic-resistant pathogens. Consequently, new strategies are needed to preserve existing agents. One approach is to seek compounds that will enhance the activity of distinct antimicrobial classes by blocking resistance mechanisms. For example, $\beta$-lactamase inhibitors extended the utility of $\beta$-lactams when delivered as combinations such as Augmentin (amoxicillin-clavulanic acid) [3], and

\footnotetext{
* Correspondence: taolu2000@yahoo.com

${ }^{1}$ Yunnan Institute of Microbiology, Yunnan University, 52 Cui Hu Bei Lu, Kunming, Yunnan 650091, PR China
}

inhibitors of efflux pumps produced synergistic inhibition of growth against tetracycline-resistant Escherichia coli when used in combination with doxycycline [4]. The conventional strategy has been to identify genes whose inactivation increases the ability of compounds to block bacterial growth (decreases in minimal inhibitory concentration, MIC) [5]. Since some compounds kill bacteria by processes that are distinct from bacteriostatic action [6,7] and since deficiencies in repair of lethal damage may not affect bacterial growth, the possibility exists that genes involved in bacterial survival are distinct from those that protect from growth inhibition. Finding genes whose products protect from the lethal effects of stress requires screening procedures that differ from those used for bacteriostatic effects.

In the present work, we used the prototype quinolone, nalidixic acid, as a probe for screening genes whose products protect $E$. coli from lethal effects of stress. 
Nalidixic acid was chosen as the initial screening agent because bacteriostatic and lethal action are distinct events that are sensitive to different drug concentrations (for review see [8]). Mutants of E. coli, obtained by Tn5mediated insertional mutagenesis, were screened for those that had the same bacteriostatic susceptibility to nalidixic acid as the wild-type strain while exhibiting greater sensitivity to the lethal action of the drug. We call this new phenotype hyperlethality. With this phenotype we could eliminate from consideration mutants with altered drug uptake, efflux, and target interactions, since these properties affect bacteriostatic activity. The decreased survival of the mutants was expected in some cases to arise from disruption of genes involved in protecting from lethal stress. The hyperlethal mutants were then examined by measuring the lethal action of several other antimicrobial and environmental stresses. This work defined a novel bactericidal phenotype and identified a diverse set of poorly characterized bacterial stressresponse genes as a new source of potential targets for antimicrobial enhancement.

\section{Methods}

\section{Bacterial strains and growth conditions}

Bacterial strains were derivatives of $E$. coli K-12. Strain AB1157 (isolate KD1045) [9] was used to construct the Tn5-insertion library. Strain DM4100 [10] was used to confirm the hyperlethal phenotype following P1mediated transduction, which was carried out according to a standard procedure [11]. In this method P1 phage lysates were prepared using the insertion mutants as donors, and the lysates were then used to infect strain DM4100 at a multiplicity of infection of 0.2. Transductants were recovered by growth on LB plates containing $25 \mu \mathrm{g} / \mathrm{ml}$ of kanamycin and $0.01 \mathrm{M}$ sodium citrate. Kanamycin-resistant transductants were tested for the hyperlethal phenotype with nalidixic acid. Bacterial cells were grown at $37^{\circ} \mathrm{C}$ either in LB broth or on LB agar plates [11].

\section{Antibacterial agents}

All chemicals were from Sigma-Aldrich Corp. (St Louis, MO, USA). Stock solutions of nalidixic acid were prepared by dissolving in $0.1 \mathrm{~N} \mathrm{NaOH}$ to yield a final concentration of $10 \mathrm{mg} / \mathrm{ml}$. Other antibiotics were dissolved in distilled water except for tetracycline and mitomycin C, which were dissolved in 50\% and 70\% ethanol, respectively. Mitomycin $\mathrm{C}$ was freshly prepared before use; other antimicrobials were stored as concentrated stock solutions at $-80^{\circ} \mathrm{C}$.

\section{Library construction and screening}

Bacteriophage lambda Tn5-tac was prepared from $E$. coli BD1527 [12] according to a standard procedure [13], and Tn5 hopping was carried out with strain AB1157 as follows: recipient cells were grown to mid- log phase $\left(\mathrm{OD}_{600}=0.3 \sim 0.5\right)$, recovered by centrifugation $(6,000 \times \mathrm{g}, 5 \mathrm{~min})$, and resuspended in ice-cold LB liquid medium containing $0.01 \mathrm{M}$ magnesium sulfate. Cells were then infected with lambda Tn5-tac at a multiplicity of infection of about 1 and incubated for 15 min at $37^{\circ} \mathrm{C}$. After incubation, fresh LB medium was added, and the cells were incubated for $2 \mathrm{hr}$ at $37^{\circ} \mathrm{C}$ for expression of kanamycin resistance. Cells were then plated on LB-agar plates containing $25 \mu \mathrm{g} / \mathrm{ml}$ of kanamycin. After incubation overnight at $37^{\circ} \mathrm{C}$, kanamycinresistant colonies were tested individually for nalidixic acid susceptibility (MIC) and lethality as described below. Mutants that were more readily killed by treatment with nalidixic acid at $20 \mu \mathrm{g} / \mathrm{ml}$ or $50 \mu \mathrm{g} / \mathrm{ml}$ for 2 hr but had MICs close to wild-type levels were considered to have a hyperlethal phenotype; they were selected for further analysis.

Determination of antimicrobial susceptibility and lethality Antimicrobial susceptibiltiy $\left(\mathrm{MIC}_{99}\right)$ was defined as the minimal concentration of antimicrobial agents that inhibited growth of $99 \%$ of the input cells. $\mathrm{MIC}_{99}$ was measured by applying $10 \mu \mathrm{l}$ of serial dilutions of midlog phase cultures $\left(\mathrm{OD}_{600}=0.3 \sim 0.5\right)$ in triplicate to $\mathrm{LB}$ agar plates containing various concentrations of antimicrobials. Colonies were counted after overnight incubation at $37^{\circ} \mathrm{C}$. The fraction of colonies recovered (relative to the CFU per $\mathrm{ml}$ on drug-free plates) was plotted against drug concentration, and $\mathrm{MIC}_{99}$ was determined by interpolation.

To measure lethality, cells were grown in LB liquid medium to mid-log phase $\left(\mathrm{OD}_{600}=0.3 \sim 0.5\right)$ at $37^{\circ} \mathrm{C}$ with shaking. Cells were split into $1-\mathrm{ml}$ aliquots in test tubes, and various concentrations of antimicrobial agents $\left(2 \times \mathrm{MIC}_{99}\right.$ to $\left.30 \times \mathrm{MIC}_{99}\right)$ were added. After incubation for $2 \mathrm{hr}$ with shaking, cells were diluted in LB liquid medium, which eliminated drug carryover, and $10 \mu \mathrm{l}$ of aliquots from the dilutions were spotted in triplicate on drug-free LB agar plates. Colonies were counted after overnight incubation at $37^{\circ} \mathrm{C}$. Lethality was expressed as percent of control relative to the CFU per $\mathrm{ml}$ at the time of drug addition. The dose that reduced CFU by $90 \%$ was taken as $\mathrm{LD}_{90}$.

For screening the mutant library, kanamycin-resistant colonies were manually replica-plated with toothpicks to a series of plates containing various concentrations of nalidixic acid and incubated overnight. Colonies exhibiting the same bacteriostatic susceptibility as the parental strain were saved for lethality measurement. Survival for each colony was measured in liquid medium after a 2-hr incubation in nalidixic acid at $20 \mu \mathrm{g} / \mathrm{ml}$ and $50 \mu \mathrm{g} / \mathrm{ml}$ as described in the previous paragraph. Colonies that exhibited decreased survival relative to the parental strain were then retested for MIC and survival as described in the previous paragraphs. Strains confirmed 
to have a hyperlethal phenotype were further characterized as described below.

\section{Identification of gene insertion sites}

Asymmetric PCR, modified from that described previously [14-16], was used to amplify E. coli genomic sequences near the ends of $\operatorname{Tn} 5$ that inserted into the genome. One primer, either Tn5R10 (5' GGG ATC CCC TAC TTG TGT AT 3') or Tn5F4568 (5' AGA ATT CCT CCC GAG ATC TG 3') was complementary to the sequence at an end of Tn5; the other primer contained a 6-nucleotide random sequence followed by TGGC (Ran5-29: 5' GTT CTA CAC GAG TCA CTG CAG NNN NNN TGG C 3'). The randomized primer binds any GCCA in the genome. However, since PCR preferentially amplifies short fragments, combination of the two primers should amplify the sequences between one Tn 5 end and the first few GCCA sequence elements. For the first 5 cycles of PCR, the annealing temperature was high $\left(58^{\circ} \mathrm{C}\right)$; consequently, the primer that was complementary to the sequence at the Tn 5 end preferentially bound to the substrate, which caused one strand of the substrate to be asymmetrically amplified. This high-temperature annealing was followed by a cycle using low annealing temperature $\left(30^{\circ} \mathrm{C}\right)$ to allow the randomized primer to bind the strand that had already been amplified. Then one high-temperature $\left(58^{\circ}\right.$ C) and one moderate-temperature $\left(44^{\circ} \mathrm{C}\right)$ cycle were alternated 12 times to amplify the sequence between the two primers. For all amplification cycles, the annealing time was $1 \mathrm{~min}$, while the denaturation $\left(94^{\circ} \mathrm{C}\right)$ and extension $\left(72^{\circ} \mathrm{C}\right)$ times were $15 \mathrm{sec}$ and $2 \mathrm{~min}$, respectively. The nucleotide sequence was then determined for PCR products that exhibited single bands following agarose gel electrophoresis. In some cases, the products of the first PCR were further amplified with repeated alternation of one high annealing temperature $\left(58^{\circ} \mathrm{C}\right)$ cycle and one moderate annealing temperature $\left(44^{\circ} \mathrm{C}\right)$ cycle in which the randomized primer was replaced with primer Fix5-29-2 (5' CTA CAC GAG TCA CTG CAG 3 '), a primer sequence that was identical to 18 of the 21 5 ' terminal nucleotides of the randomized primer. DNA sequences obtained were used as query probes to search the $E$. coli K-12 genome sequence database for identifying transposon insertion sites.

\section{Lethality of environmental stresses}

The susceptibility of bacterial cells to UV irradiation was tested by applying serial dilutions of mid-log phase $\left(\mathrm{OD}_{600}=0.3 \sim 0.5\right)$ cultures to agar plates that were irradiated with an Ultraviolet Crosslinker CL-1000 (UVP) at a dose of $2000 \mu \mathrm{J} / \mathrm{cm}^{2}$ in a dark room. The plates were then covered with aluminium foil and incubated overnight at $37^{\circ} \mathrm{C}$. For other stressors, mid-log phase cells were treated with $2 \mathrm{mM} \mathrm{H}_{2} \mathrm{O}_{2}$ (cells were resuspended in $0.9 \%$ saline before treatment), $10 \%$ sodium dodecyl sulfate (SDS), or high temperature $\left(52^{\circ} \mathrm{C}\right)$ for $15 \mathrm{~min}$. Serial dilutions were then prepared, and $10-\mu \mathrm{l}$ of aliquots from the dilutions were spotted in triplicate on plates and incubated at $37^{\circ} \mathrm{C}$ overnight. The sensitivity of cells to the lethal effects of these stressors was expressed as percent survival of treated cells relative to that of untreated cells determined at the time of treatment $\left(\mathrm{LD}_{90}\right.$ could not be used because many of the mutant-stressor combinations did not reduce survival sufficiently).

\section{Complementation of hyperlethality by cloned genes}

All DNA manipulations were carried out according to procedures described previously [13]. The emrK and $y c j U$ genes with their promoter regions were amplified by PCR using chromosomal DNA isolated from DM4100 as templates and cloned into pBR322. The primers used were 5'-TAG GAA TTC ATC TCC CTT CTC CCT GTA GT-3' and 5'-TAA GTC GAC ATT CTT TGT GCC AAC CTG-3' for emrK, and 5'-TGC GAA TTC CTG CTG ACC CAA AGT TAT-3' and 5'TAG CTG CAG TCA CCT CTT TGG CGA TT-3' for $y c j U$. Plasmids containing wild-type $y c j W, y r b B$, and $y b c M$ were from the ASKA library [17]. The plasmids were placed in the corresponding mutant strains, as well as in the wild-type strain DM4100, by electroporation. The strains harboring the plasmids were then tested for nalidixic acid lethality. For $y c j W, y r b B$, and $y b c M$, the expression was induced by adding $1 \mathrm{mM}$ of IPTG $2 \mathrm{hr}$ before nalidixic acid treatment.

\section{Results and Discussion}

\section{Screening for mutants exhibiting hyperlethality to} nalidixic acid

During the course of evolution, bacteria have acquired a variety of genetic networks that provide protection from stress. For example, in E. coli more than 30 two-component systems detect the environment and cause changes in the expression of large numbers of genes [18]. To find genes that are specifically involved in protecting from the lethal action of antibiotics, as opposed to genes that simply limit drug uptake or enhance efflux, we screened a library of transposon-generated mutants for a hyperlethal phenotype (more readily killed by nalidixic acid with no change in bacteriostatic susceptibility, MIC). From about 800 insertion mutants we recovered 14 that exhibited the phenotype. To establish that the hyperlethal phenotype arose from transposon insertion, each of the mutations was transferred to a second strain of E. coli by P1mediated transduction. Transductants from each mutant strain were more readily killed by nalidixic acid (Fig. 1) while displaying less than a 2 -fold variation in $\mathrm{MIC}_{99}$ relative to the wild-type parent (Table 1). Thus, the Tn5insertion was necessary and sufficient for the hyperlethal phenotype with all 14 mutants tested. 


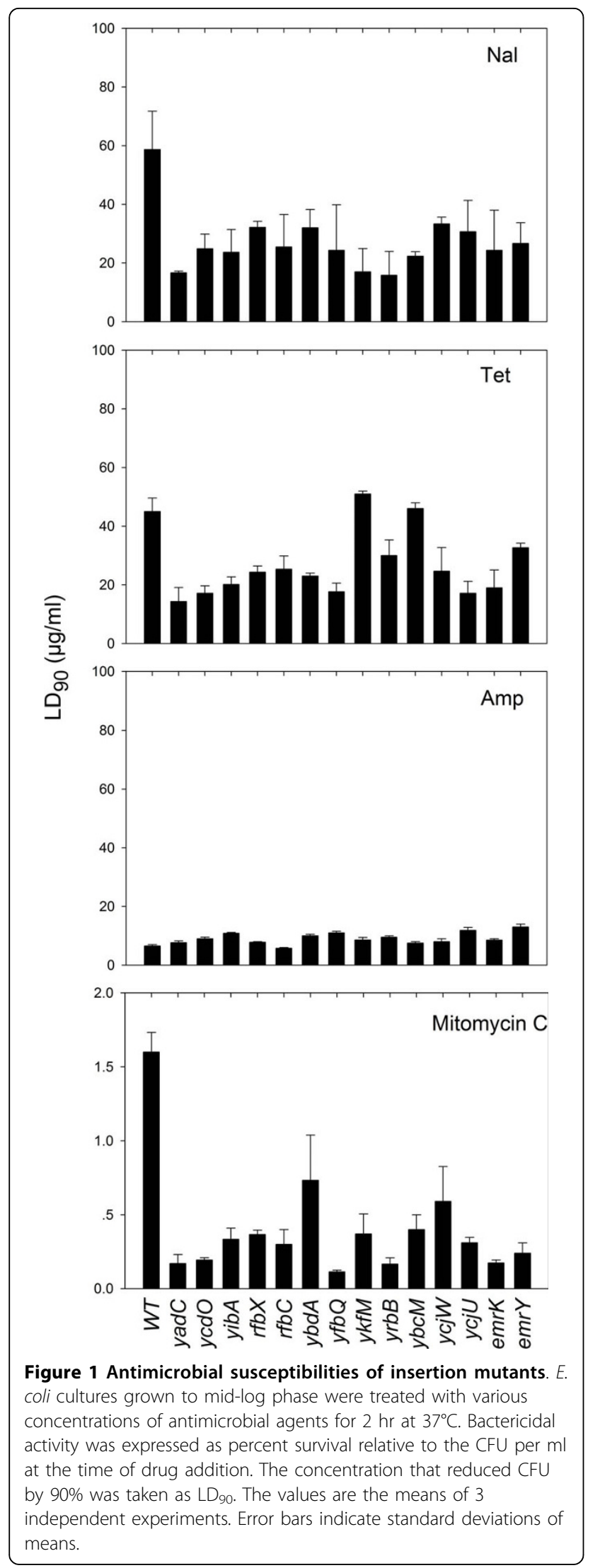

Table 1 Properties of genes that reduce the lethal effects of stress.

\begin{tabular}{|c|c|c|c|}
\hline Strain & $\begin{array}{l}\mathrm{MIC}_{99} \text { of } \mathrm{Nal} \\
(\mu \mathrm{g} / \mathrm{ml})^{\mathrm{a}}\end{array}$ & $\begin{array}{l}\text { Site of } \\
\text { insertion }\end{array}$ & $\begin{array}{l}\text { Functional annotation of } \\
\text { disrupted genes }\end{array}$ \\
\hline DM4100 & $4.5 \pm 0.3$ & $\begin{array}{l}\text { NA (wild- } \\
\text { type) }\end{array}$ & NA \\
\hline TL17 & $3.1 \pm 0.1$ & yadc & Fimbrial-like protein \\
\hline TL18 & $4.6 \pm 0.3$ & $y c d O$ & Putative lipoprotein \\
\hline TL19 & $4.2 \pm 0.6$ & yibA & $\begin{array}{l}\text { Predicted lyase containing HEAT- } \\
\text { repeat }\end{array}$ \\
\hline TL20 & $4.6 \pm 0.4$ & $r f b X$ & $\begin{array}{l}\text { RfbX lipopolysaccharide PST } \\
\text { transporter }\end{array}$ \\
\hline TL21 & $4.8 \pm 0.2$ & $r f b C$ & $\begin{array}{l}\text { dTDP-4-deoxyrhamnose-3,5- } \\
\text { epimerase }\end{array}$ \\
\hline TL22 & $4.7 \pm 0.1$ & $y b d A$ & $\begin{array}{l}\text { Permease (major facilitator } \\
\text { superfamily (MFS) of } \\
\text { transporters) }\end{array}$ \\
\hline TL23 & $3.7 \pm 0.3$ & $y f b Q$ & Predicted aminotransferase \\
\hline TL24 & $3.3 \pm 0.2$ & $y k f M$ & Predicted protein \\
\hline TL25 & $3.0 \pm 0.2$ & yrbB & Predicted NTP-binding protein \\
\hline TL26 & $5.3 \pm 0.3$ & $y b c M$ & ARAC-type regulatory protein \\
\hline TL28 & $3.4 \pm 0.1$ & $y c j W$ & $\begin{array}{l}\text { Putative LACI-type transcriptional } \\
\text { regulator }\end{array}$ \\
\hline TL157 & $4.1 \pm 0.5$ & $y c j U$ & Putative $\beta$-phosphoglucomutase \\
\hline TL158 & $4.0 \pm 0.6$ & emrk & $\begin{array}{l}\text { Putative membrane fusion } \\
\text { protein }\end{array}$ \\
\hline TL162 & $4.4 \pm 0.6$ & emrY & $\begin{array}{l}\text { Putative multidrug MFS } \\
\text { transporter }\end{array}$ \\
\hline
\end{tabular}

${ }^{\mathrm{a}} \mathrm{MIC}_{99}$ was measured by applying serial dilutions of mid-log phase cultures to agar plates containing various concentrations of nalidixic acid followed by incubation, colony number determination, and $\mathrm{MIC}_{99}$ estimation as described in Methods. The values shown are the means of 3 independent experiments with standard deviations as indicated. Abbreviations: Nal: nalidixic acid; NA: not applicable.

To identify the genes inactivated by Tn 5 insertion, asymmetric PCR was used to amplify the sequences near the ends of Tn5 using a protocol modified from previously published reports [14-16]. Nucleotide sequence determination of the PCR products then identified 14 different genes (Table 1). Only one of these genes $(y c j U$, also called $p g m B)$ appeared in the list of genes identified previously as being involved in affecting the bacteriostatic action of quinolones [5]. The $y c j U$ mutation caused cells to be only slightly more susceptible to nalidixic acid than the wild-type strain in our bacteriostatic measurement (Table $1, \mathrm{MIC}_{99} 4.1 \mu \mathrm{g} / \mathrm{ml} \mathrm{vs}$. $4.5 \mu \mathrm{g} / \mathrm{ml}$ ). Thus, $y c j U$ may not belong in the set previously identified as having a low MIC [5]. The two-fold drop in $\mathrm{LD}_{90}$, from $59 \mu \mathrm{g} / \mathrm{ml}$ to $31 \mu \mathrm{g} / \mathrm{ml}$ (Fig. 1), qualified it as a gene with a hyperlethal phenotype.

Mutant susceptibility to other antimicrobial agents and environmental stressors

To determine whether the hyperlethal phenotype was restricted to quinolones, we examined the response of the mutants to a variety of other stresses. When tetracycline was tested, we found that, except for two strains 
TL24 ( $y k f M:: \operatorname{Tn} 5)$ and TL26 ( $y b c M:: \operatorname{Tn} 5)$, the mutants were more readily killed ( $\mathrm{LD}_{90}$ was about half the wildtype value, Fig. 1). Increased lethality was not observed for the $\beta$-lactam ampicillin (Fig. 1). Thus, increased killing of the mutants by antimicrobial agents was not restricted to quinolones, but it was also not universal.

When the DNA damaging agent mitomycin $C$ was tested, all of the mutants were more readily killed than wild-type cells (for some genes $\mathrm{LD}_{90}$ was $10 \%$ of wildtype values, many were in the 20 to $30 \%$ range, and two were close to $50 \%$, Fig. 1). More than half of the mutants were more readily killed by UV irradiation than the wild-type strain (Fig. 2). Genes not involved in protecting cells from the effects of UV irradiation were $r f b X, y b d A, y f b Q, y k f M$, and $y c j W$. Nine others were involved in protecting cells from the effects of nalidixic acid, mitomycin $\mathrm{C}$, and UV. Thus, many of the genes are involved in facilitating survival of $E$. coli cells exposed to DNA-damaging agents.

The effect of hydrogen peroxide was also examined, since it has recently been implicated in the lethal action of multiple antibiotics [6,7]. After treatment with $2 \mathrm{mM}$ $\mathrm{H}_{2} \mathrm{O}_{2}$ for 15 min, all mutants showed decreased survival compared to wild-type strain DM4100 (for many mutants survival was 20 to $30 \%$ that of the wild-type strain, Fig. 2). We also examined the effects of two other environmental stresses, exposure to high temperature and to the ionic detergent sodium dodecyl sulfate (SDS). When the set of mutants was exposed to high temperature $\left(52^{\circ} \mathrm{C}\right)$, no substantial difference among the mutants was observed for heat-induced death (Fig. 2). With $10 \%$ SDS, the effect of the mutations on survival varied. Some mutants ( $y a d C, y b d A, y f b Q, y k f M, y r b B$, $y b c M$, and $e m r K)$ were less susceptible to killing than wild-type $E$. coli, while $y c d O$, $y i b A$, and $r f b C$ mutants were more readily killed (Fig. 2).

In summary, 14 mutant genes were associated with hyperlethality to nalidixic acid and were more readily killed by mitomycin $\mathrm{C}$ and peroxide; 9 were more readily killed by UV irradiation. Only 3 of the mutants were more readily killed by SDS, none by high temperature. Below we consider what has been reported previously about the diverse set of genes identified by our screening procedure. None of that information leads to an expectation of hyperlethality to nalidixic acid.

Putative function of genes exhibiting hyperlethality to nalidixic acid

Eight of the mutant genes $(y a d C, r f b X, r f b C, y c d O, y r b B$, $y b d A$, emrK, and $e m r Y$ ) were annotated in Genbank as outer membrane proteins or proteins whose function is related to the outer membrane. The $\mathrm{MIC}_{99} \mathrm{~S}$ of these mutants for nalidixic acid were in the same range as that of the wild-type strain; consequently, hyperlethality caused by these mutations was unlikely to be due to

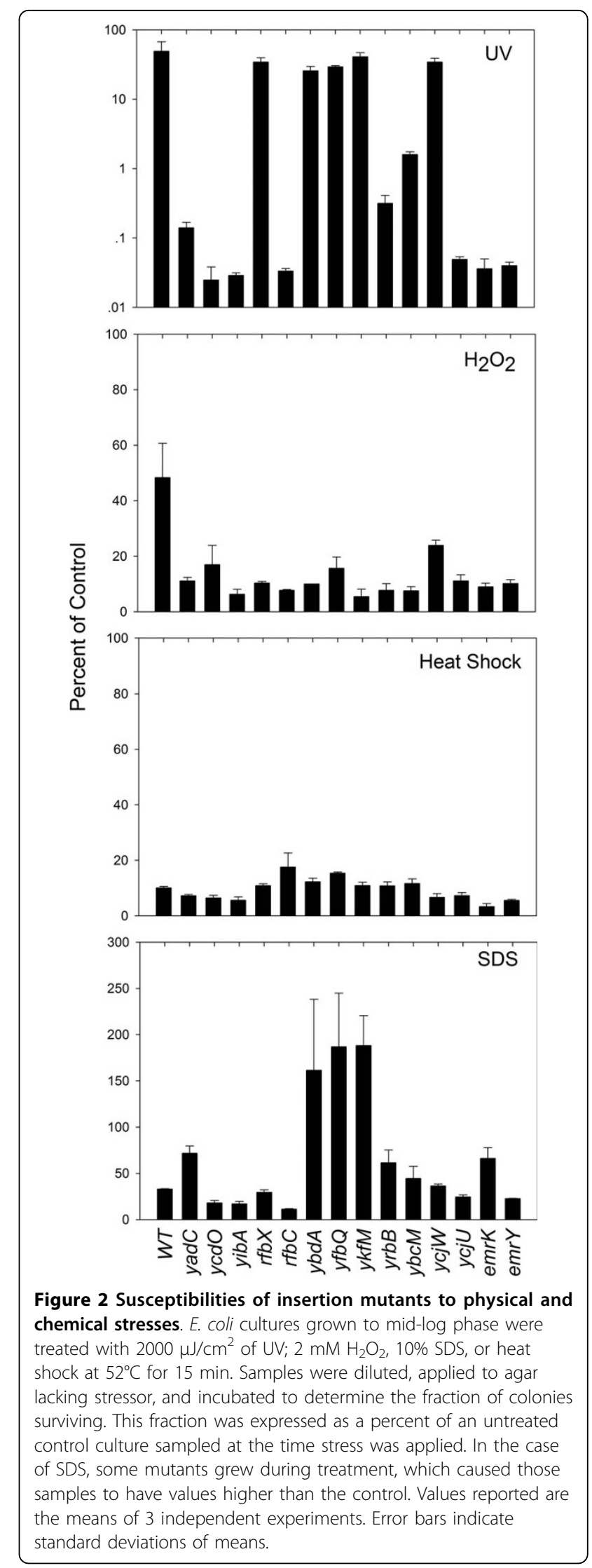


increased accumulation of drug. Since the genes were involved in protecting from the effects of nalidixic acid, mitomycin $\mathrm{C}$, and hydrogen peroxide, it is likely that protection from UV irradiation also occurred at the level of downstream effects of irradiation rather than through screening cells from UV light.

The yadC mutant, which was among the more sensitive to DNA damaging agents, was considerably less sensitive than the wild-type strain to SDS. YadC is a fimbrial-like protein whose amino acid sequence suggests that it may contain $\beta$-barrel structure(s) [19]. In $E$. coli, pili are adherence factors that could, in principle, protect some cells in a population from antimicrobial treatment. However, we detected no difference with respect to cellular aggregation when the yadC mutant and the wild-type strain, growing exponentially, were examined by light microscopy (not shown). Thus, the hyperlethal phenotype of the mutant was not likely to be due to lack of cellular self-association. yadC is induced immediately after exposure to the biocide polyhexamethylene biguanide [20], which is consistent with its involvement in a cellular response to stress.

The two $r f b$ mutants were strikingly different in their response to UV: the $r f b X$ mutant showed little effect, while the $r f b C$ mutant was one of the most susceptible (Fig. 2). RfbX, also known as WzxB, is a member of the polysaccharide transporter (PST) family [21], and hydropathy analysis suggests that RfbX has 12 transmembrane segments [22]. $r f b C$ encodes dTDP-4-dehydrorhamnose 3,5 -epimerase [23]. Although the $r f b$ genes are thought to be involved in O-antigen biosynthesis in enteric bacteria, such as Salmonella, Shigella, Klebsiella, and some serovars of E. coli [24], that feature may be irrelevant to the current work, since $E$. coli $\mathrm{K}-12$ does not normally express a functional $\mathrm{O}$-antigen due to defects in the $r f b$ gene cluster $[25,26]$. The fact that $r f b X$ is induced when treated with polyhexamethylene biguanide [20] suggests that it may be involved in a cellular stress response.

The $y c d O$ mutant was the most readily killed by UV irradiation (Fig. 2). YcdO is a monomeric, membraneassociated protein that contains a type I signal peptide and is transported to the periplasm with high efficiency [27]. Since YcdO is induced at low $\mathrm{pH}$ due to phosphorylation of the CpxR component of the CpxAR two-component response regulator [28-30], it may be involved in bacterial envelope stress responses mediated by the CpxAR pathway.

$\operatorname{YrbB}(\mathrm{MlaB})$ is predicted to be a nucleotide-binding protein that contains a STAS domain [31]. YrbB is a component of an $\mathrm{ABC}$ transport system that maintains lipid asymmetry in the Gram-negative outer membrane by preventing surface exposure of phospholipids [32]. Although the YrbB mutant is more sensitive than the wild-type strain to the presence of EDTA-SDS, it does not show hypersusceptibility to erythromycin, rifampicin, bacitracin, or novobiocin [32]. These data indicate that the $y r b B$ mutation does not change the permeablility to most compounds, which is consistent with our finding that the $y r b B$ mutation did not change the bacteriostatic effects of nalidixic acid.

$y b d A$, emrK, and emrY are postulated to encode efflux pumps, although MIC determinations with nalidixic acid showed no evidence that the mutations affected efflux (Table 1). The YbdA protein is a member of the major facilitator superfamily (MFS) of transporters [33], while EmrK and EmrY show sequence similarity to members of the EmrAB-TolC drug efflux system. The two emr mutants were exceptionally sensitive to mitomycin $\mathrm{C}$ (Fig. 1), UV irradiation, and $\mathrm{H}_{2} \mathrm{O}_{2}$ (Fig. 2). The $y b d A$ and $e m r K$ mutants were among the least susceptible to the lethal effects of SDS (Fig. 2), as expected of efflux mutants. Perhaps the ErmK, ErmY, and YbdA proteins normally pump out toxic metabolites induced by DNA damage.

Two genes, $y b c M$ and $y c j W$, are predicted to be involved in cell regulation. YbcM is a putative DNAbinding transcriptional regulator that is induced by the biocide polyhexamethylene biguanide [20]; in Yersinia enterocolitica a homolog of $y b c M$ is induced by low temperature [34]. These properties are consistent with YbcM being involved in bacterial stress responses. YcjW is a putative LacI-type transcriptional regulator. Although the biological role of $\mathrm{YcjW}$ is unknown, $y c j W$ transcripts accumulate in a strain harboring wild-type relA but not in a relA mutant after treatment with 4azaleucine, an inhibitor that interferes with translation [35]. These data suggest that YcjW may be involved in the bacterial stringent response.

Three other genes, $y c j U, y i b A$, and $y f b Q$, encode putative cytosolic proteins of unknown function. The $y c j U$ mutant is among the most sensitive to UV irradiation (Fig. 2). YcjU has been annotated in sequence data bases as a putative $\beta$-phosphoglucomutase that belongs to the superfamily of haloacid dehalogenase (HAD)-like hydrolases. In vitro, YcjU hydrolyzes small phosphodonors [36], which suggest that the protein is likely to have other physiological roles. The yibA mutant was among the most sensitive to UV irradiation and $\mathrm{H}_{2} \mathrm{O}_{2}$ (Fig. 2). YibA is a predicted lyase containing a HEAT-repeat, which forms a rod-like helical structure in proteins. Transcription profiling experiments suggested that $y i b A$ may belong to the $\sigma^{32}$ regulon [37], whose genes are expressed in E. coli in response to heat shock. Thus, the role of YibA in antimicrobial susceptibility may be exerted through alternative sigma factor-regulated stress responses. However, the $y i b A$ mutant was not particularly sensitive to high temperature. A third mutant, in $y f b Q$, was the most sensitive to mitomycin C. The only 
information available refers to the gene product as a potential aminotransferase.

\section{Reactive oxygen species-mediated response to lethal} antimicrobials

Although no clear metabolic connection exists among the genes we identified, some guidance can be gained from the recent proposal that lethal antimicrobials share a common cell death pathway involving a reactive oxygen cascade [6,7]. The lethal activity of a variety of antimicrobials, including the fluoroquinolone norfloxacin, is accompanied by an increase in hydroxyl radical, and lethal activity is greatly reduced by treating $E$. coli cells with agents that block the accumulation of hydroxyl radical [6]. The idea emerged that lethal antimicrobials act in part by generating a signal that causes an accumulation of superoxide, which reacts with iron-sulfur clusters to release peroxide and iron. Peroxide and iron then form highly toxic hydroxyl radicals through the Fenton reaction. Superoxide can also be converted to peroxide by superoxide dismutase and by spontaneous dismutation. The resulting increase in peroxide would contribute to the formation of hydroxyl radical. In support of this idea, we found that deletion of both superoxide dismutase genes reduced the lethality of norfloxacin [38]. As expected, a deficiency of catalase, which converts peroxide to water, led to an increase in the lethality of norfloxacin [38]. Mutations in genes that normally protect from the accumulation of reactive oxygen species would be recovered by our screen for hyperlethality to nalidixic acid. Such mutants are expected to also be more readily killed by other DNA damaging agents, such as mitomycin $\mathrm{C}$, peroxide, and UV irradiation, as seen for 9 of the 14 of the genes we identified.

\section{Complementation of hyperlethality by cloned genes}

To determine whether the hyperlethal phenotype of the mutants was caused by deficiency of the mutant genes rather than polar effects due to Tn5 insertion, we selected several mutants for complementation using wild-type genes cloned into plasmids. We focused on representatives from three groups (membrane and related proteins $(e m r K, y r b B)$, cytosolic enzymes $(y c j U)$, and regulators $(y c j W, y b c M))$. In each case, complementation was observed (Fig. 3). Thus, at least for this selection of genes it is likely that the gene products contributed to reducing the lethal effects of nalidixic acid. While these data do not assure that complementation will occur in the other cases, they give us confidence to move forward with the study of the bacterial response to lethal stress. We note in some cases paradoxical survival occurred at high concentrations of nalidixic acid. This phenomenon, which is unexplained, is commonly observed with quinolones [39].

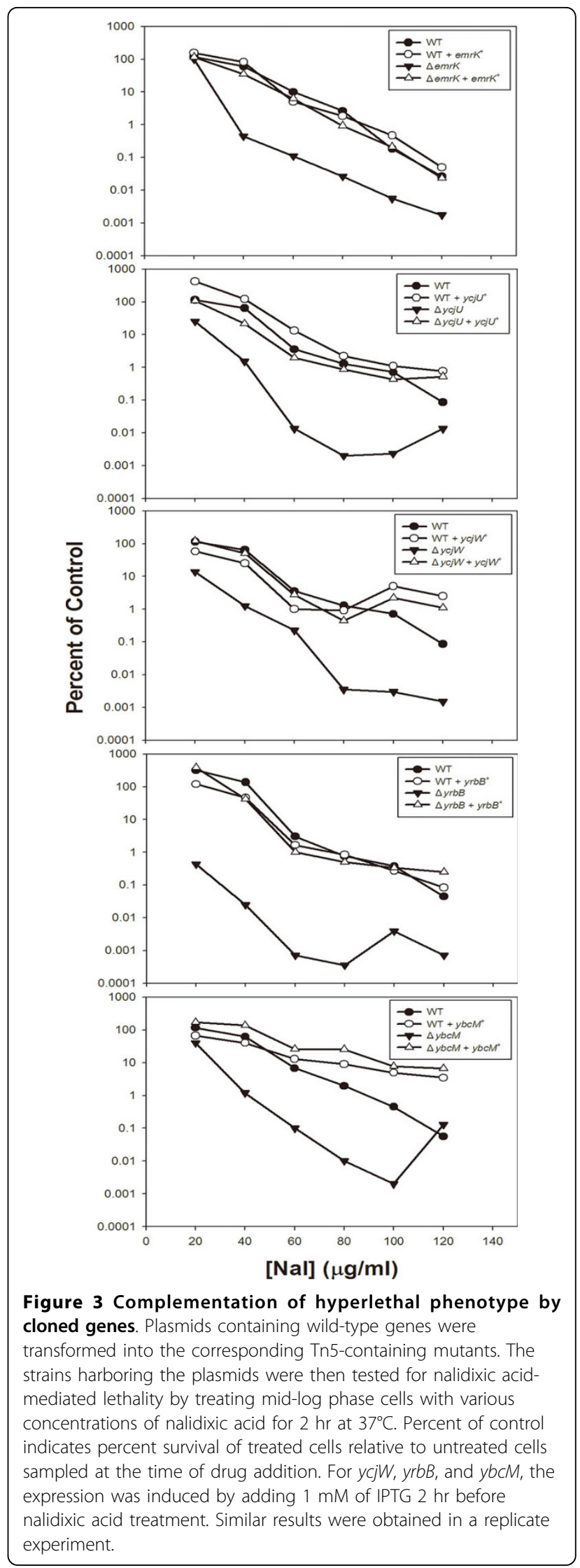




\section{Conclusions}

The present work described a novel screening process for identifying genes involved in protecting E. coli from quinolone-mediated death due to events occurring after formation of quinolone-gyrase-DNA complexes. Using this screen we identified 14 poorly characterized genes. Scattered evidence suggests that many of these genes are linked to protective stress responses, which is supported by our finding that mutations in these putative protective genes resulted in decreased survival following treatment with several stressors. The diverse set of genes described may serve as potential targets for future screening of small-molecule antimicrobial potentiators.

\section{Acknowledgements}

This work was supported by National Natural Science Foundation of China (Grant No. 30860012) and Natural Science Foundation of Yunnan Province of China (Grant No. 2005C0007R) to T.L, NIH grants Al35257 and Al 073491 to K.D, and NIH grant Al068014 to XZ.

\section{Author details}

${ }^{1}$ Yunnan Institute of Microbiology, Yunnan University, 52 Cui Hu Bei Lu, Kunming, Yunnan 650091, PR China. ${ }^{2}$ Public Health Research Institute, New Jersey Medical School, UMDNJ, 225 Warren Street, Newark, NJ 07103, USA.

\section{Authors' contributions}

XH screened for hypersusceptible mutants, helped identifying insertion sites, and measured susceptibility of mutants to antimicrobial agents and other stresses. AD participated in writing the manuscript. MM participated in mutant screening. JW identified genes containing Tn5 insertions. KD participated in initial project design, supervised all work performed at PHRI, and participated in writing the manuscript. $X Z$ participated in project design, screened for mutants, and participated in writing the manuscript. $T L$ participated in initial project design, supervised all work performed at YNU, constructed the insertion library, screened for mutants, carried out P1transduction, and carried out primary writing of manuscript. All authors read and approved the final manuscript.

Received: 3 July 2009

Accepted: 4 February 2010 Published: 4 February 2010

\section{References}

1. Levy SB: Antibiotic resistance-the problem intensifies. Adv Drug Deliv Rev 2005, 57(10):1446-1450.

2. Levy SB, Marshall B: Antibacterial resistance worldwide: causes, challenges and responses. Nat Med 2004, 10(12 Suppl):S122-129.

3. Buynak JD: Understanding the longevity of the beta-lactam antibiotics and of antibiotic/beta-lactamase inhibitor combinations. Biochem Pharmacol 2006, 71(7):930-940.

4. Nelson ML, Levy SB: Reversal of tetracycline resistance mediated by different bacterial tetracycline resistance determinants by an inhibitor of the Tet(B) antiport protein. Antimicrobial agents and chemotherapy 1999, 43(7):1719-1724.

5. Tamae C, Liu A, Kim K, Sitz D, Hong J, Becket E, Bui A, Solaimani P, Tran KP, Yang $\mathrm{H}$, et al: Determination of antibiotic hypersensitivity among 4,000 single-gene-knockout mutants of Escherichia coli. Journal of bacteriology 2008, 190(17):5981-5988.

6. Kohanski MA, Dwyer DJ, Hayete B, Lawrence CA, Collins JJ: A common mechanism of cellular death induced by bactericidal antibiotics. Cell 2007, 130(5):797-810.

7. Dwyer DJ, Kohanski MA, Hayete B, Collins JJ: Gyrase inhibitors induce an oxidative damage cellular death pathway in Escherichia coli. Mol Syst Biol 2007, 3:91

8. Drlica K, Malik M, Kerns RJ, Zhao X: Quinolone-mediated bacterial death. Antimicrobial agents and chemotherapy 2008, 52(2):385-392.
9. Bachmann BJ: Pedigrees of some mutant strains of Escherichia coli K-12. Bacteriol Rev 1972, 36(4):525-557.

10. Sternglanz R, DiNardo S, Voelkel KA, Nishimura Y, Hirota $Y$, Becherer $K$, Zumstein L, Wang JC: Mutations in the gene coding for Escherichia coli DNA topoisomerase I affect transcription and transposition. Proceedings of the National Academy of Sciences of the United States of America 1981, 78(5):2747-2751

11. Miller J: Experiments in Molecular Genetics. Cold Spring Harbor, New York: Cold Spring Harbor Laboratory Press 1972.

12. Chow WY, Berg DE: Tn5tac1, a derivative of transposon Tn5 that generates conditional mutations. Proceedings of the National Academy of Sciences of the United States of America 1988, 85(17):6468-6472.

13. Sambrook J, Russel DW: Molecular Cloning: A Laboratory Manual. Cold Spring Harbor, New York: Cold Spring Harbor Laboratory Press, 32001.

14. Liu YG, Mitsukawa N, Oosumi T, Whittier RF: Efficient isolation and mapping of Arabidopsis thaliana T-DNA insert junctions by thermal asymmetric interlaced PCR. Plant J 1995, 8(3):457-463.

15. Liu YG, Mitsukawa N, Whittier RF: Rapid sequencing of unpurified PCR products by thermal asymmetric PCR cycle sequencing using unlabeled sequencing primers. Nucleic acids research 1993, 21(14):3333-3334.

16. Liu YG, Whittier RF: Thermal asymmetric interlaced PCR: automatable amplification and sequencing of insert end fragments from P1 and YAC clones for chromosome walking. Genomics 1995, 25(3):674-681.

17. Kitagawa $M$, Ara $T$, Arifuzzaman M, loka-Nakamichi T, Inamoto $E$, Toyonaga $\mathrm{H}$, Mori $\mathrm{H}$ : Complete set of ORF clones of Escherichia coli ASKA library (A Complete Set of E. coli K-12 ORF Archive): Unique Resources for Biological Research. DNA Res 2005, 12(5):291-299.

18. Mizuno T: Compilation of all genes encoding two-component phosphotransfer signal transducers in the genome of Escherichia coli. DNA Res 1997, 4(2):161-168.

19. Zhai $Y$, Saier MH Jr: The beta-barrel finder (BBF) program, allowing identification of outer membrane beta-barrel proteins encoded within prokaryotic genomes. Protein Sci 2002, 11(9):2196-2207.

20. Allen MJ, White GF, Morby AP: The response of Escherichia coli to exposure to the biocide polyhexamethylene biguanide. Microbiology (Reading, England) 2006, 152(Pt 4):989-1000.

21. Paulsen IT, Beness AM, Saier MH Jr: Computer-based analyses of the protein constituents of transport systems catalysing export of complex carbohydrates in bacteria. Microbiology (Reading, England) 1997, 143(Pt 8):2685-2699.

22. Liu D, Cole RA, Reeves PR: An O-antigen processing function for Wzx ( $\mathrm{ffbX}$ ): a promising candidate for O-unit flippase. Journal of bacteriology 1996, 178(7):2102-2107.

23. Yao Z, Valvano MA: Genetic analysis of the O-specific lipopolysaccharide biosynthesis region ( $\mathrm{rfb}$ ) of Escherichia coli K-12 W3110: identification of genes that confer group 6 specificity to Shigella flexneri serotypes $Y$ and 4a. Journal of bacteriology 1994, 176(13):4133-4143.

24. Schnaitman CA, Klena JD: Genetics of lipopolysaccharide biosynthesis in enteric bacteria. Microbiological reviews 1993, 57(3):655-682.

25. Liu D, Reeves PR: Escherichia coli K12 regains its $\mathrm{O}$ antigen. Microbiology (Reading, England) 1994, 140(Pt 1):49-57.

26. Stevenson G, Neal B, Liu D, Hobbs M, Packer NH, Batley M, Redmond JW, Lindquist $L$, Reeves $P$ : Structure of the $O$ antigen of Escherichia coli K-12 and the sequence of its rfb gene cluster. Journal of bacteriology 1994, 176(13):4144-4156.

27. Sturm A, Schierhorn A, Lindenstrauss $U$, Lilie $H$, Bruser T: YcdB from Escherichia coli reveals a novel class of Tat-dependently translocated hemoproteins. The Journal of biological chemistry 2006, 281(20):13972-13978

28. Stancik LM, Stancik DM, Schmidt B, Barnhart DM, Yoncheva YN, Slonczewski JL: pH-dependent expression of periplasmic proteins and amino acid catabolism in Escherichia coli. Journal of bacteriology 2002, 184(15):4246-4258.

29. Maurer LM, Yohannes E, Bondurant SS, Radmacher M, Slonczewski JL: pH regulates genes for flagellar motility, catabolism, and oxidative stress in Escherichia coli K-12. Journal of bacteriology 2005, 187(1):304-319.

30. Cao J, Woodhall MR, Alvarez J, Cartron ML, Andrews SC: EfeUOB (YcdNOB) is a tripartite, acid-induced and CpxAR-regulated, low-pH Fe2+ transporter that is cryptic in Escherichia coli K-12 but functional in E. coli 0157:H7. Molecular microbiology 2007, 65(4):857-875. 
31. Aravind $\mathrm{L}$, Koonin EV: The STAS domain - a link between anion transporters and antisigma-factor antagonists. Curr Biol 2000, 10(2): R53-55.

32. Malinverni JC, Silhavy TJ: An ABC transport system that maintains lipid asymmetry in the gram-negative outer membrane. Proceedings of the National Academy of Sciences of the United States of America 2009, 106(19):8009-8014.

33. Pao SS, Paulsen IT, Saier MH Jr: Major facilitator superfamily. Microbiol Mol Biol Rev 1998, 62(1):1-34.

34. Bresolin G, Neuhaus K, Scherer S, Fuchs TM: Transcriptional analysis of long-term adaptation of Yersinia enterocolitica to low-temperature growth. Journal of bacteriology 2006, 188(8):2945-2958.

35. Sabina J, Dover N, Templeton LJ, Smulski DR, Soll D, LaRossa RA: Interfering with different steps of protein synthesis explored by transcriptional profiling of Escherichia coli K-12. Journal of bacteriology 2003, 185(20):6158-6170.

36. Kuznetsova E, Proudfoot M, Gonzalez CF, Brown G, Omelchenko MV, Borozan I, Carmel L, Wolf Yl, Mori H, Savchenko AV, et al: Genome-wide analysis of substrate specificities of the Escherichia coli haloacid dehalogenase-like phosphatase family. The Journal of biological chemistry 2006, 281(47):36149-36161.

37. Zhao K, Liu M, Burgess RR: The Global Transcriptional Response of Escherichia coli to Induced $\sigma^{32}$ Protein Involves $\sigma^{32}$ Regulon Activation Followed by Inactivation and Degradation of $\sigma^{32}$ in vivo. The Journal of biological chemistry 2005, 280(18):17758-17768.

38. Wang $X$, Zhao $X$ : Contribution of oxidative damage to antimicrobial lethality. Antimicrobial agents and chemotherapy 2009, 53(4):1395-1402.

39. Malik M, Capecci J, Drlica K: Lon protease is essential for paradoxical survival of Escherichia coli exposed to high concentrations of quinolone. Antimicrobial agents and chemotherapy 2009, 53(7):3103-3105.

doi:10.1186/1471-2180-10-35

Cite this article as: Han et al.: Escherichia coli genes that reduce the lethal effects of stress. BMC Microbiology 2010 10:35.

\section{Submit your next manuscript to BioMed Central and take full advantage of:}

- Convenient online submission

- Thorough peer review

- No space constraints or color figure charges

- Immediate publication on acceptance

- Inclusion in PubMed, CAS, Scopus and Google Scholar

- Research which is freely available for redistribution

Submit your manuscript at www.biomedcentral.com/submit
Biomed Central 